\title{
QUIEN PECA Y REZA EMPATA: TENSIÓN ENTRE EL DISCURSO UNIVERSAL Y LAS PRÁCTICAS REGIONALES EN LA IGLESIA CATÓLICA EN RELACIÓN CON EL NEOLIBERALISMO LATINOAMERICANO ${ }^{1}$
}

\author{
Andrés Boteroa \\ ${ }^{a}$ Abogado y filósofo. Profesor titular de la Escuela de Filosofía de la Universidad \\ Industrial de Santander. Bucaramanga, Colombia.E-mail: aboterob@uis.edu.co \\ Orcid:0000-0002-2609-0265 \\ Javier Aguirre ${ }^{b}$ \\ ${ }^{b}$ Abogado y filósofo. Profesor titular de la Escuela de Filosofía de la Universidad \\ Industrial de Santander. Bucaramanga, Colombia.E-mail: jaguirre@uis.edu.co \\ Orcid:0000-0002-3734-227X \\ Juan Almeydac
}

cFilósofo de la Universidad Industrial de Santander. Profesor de la Escuela de Filosofía de la Universidad Industrial de Santander. Bucaramanga, Colombia.

E-mail: juanalmeyda96@gmail.com

Orcid:0000-0002-6463-6388

http://dx.doi.org/10.1590/0102-137174/113

\section{Introducción}

En el actual contexto globalizado es ineludible cuestionar el modo en que cada actor se relaciona con el sistema

1 Este artículo es resultado de la investigación financiada con recursos del proyecto 2808 (código SIVIE), "La libertad como alternativa al neoliberalismo. Los conceptos de libertad desde los filósofos Brown, Han, Laval y Dardot, como alternativa a la concepción de libertad que la racionalidad productora de la subjetividad del homo oeconomicus impone en la sociedad occidental contemporánea”, de la Universidad Industrial de Santander (Colombia). Esta investigación se realizó bajo el método documental-bibliográfico, con enfoque hermenéutico. 
hegemónico dominante. La Iglesia católica ${ }^{2}$ no es la excepción; muy por el contrario, ese ha sido uno de los principales puntos de preocupación del Papa Francisco I desde que llegó a tomar el control del Vaticano. Así, debido a las actuales crisis que el mundo debe confrontar, es menester, según el Sumo Pontífice, que se piense en modos alternativos para propender a una conservación de la humanidad a partir de un estilo de vida menos nocivo para la Tierra y sus habitantes.

Así pues, la Iglesia católica ha construido un mensaje global, esto es, con pretensiones de validez para toda la humanidad en general y para todos los católicos del mundo en especial, en el que presenta críticas directas y severas al estilo de vida que promueve el neoliberalismo globalizado que actualmente absorbe y corroe todas las dimensiones del ser humano. En un claro retorno a la Doctrina Social de la Iglesia (DSI), que se remonta a la Rerum Novarum (1891) de León XIII, el Papa Francisco actualiza los principios 138 sociales de dicha doctrina para darle un contenido humano a la actual sociedad del rendimiento ${ }^{3}$ que amenaza con acabar con la creación de Dios.

No obstante, este mismo contexto globalizado ha logrado que el mundo, a pesar de la hipercomunicación existente, se fragmente y se divida cada vez más, haciendo de la unidad y la cooperación un sinónimo únicamente compatible con el de alianza mercantil y económica. Esto último, junto con un pasado histórico predominado por un conflicto ideológico, ha resultado en que una buena parte de las actuales prácticas católicas locales que se desarrollan en América Latina sean producto de una necesidad económica y política de control, lo que va de la mano de una

2 En este escrito, se usa la mayúscula inicial en la palabra "Iglesia" para hacer
referencia al Vaticano y a la teoría y práctica universales de la religión católica;
mientras que "iglesia", con minúscula inicial, hace referencia a las prácticas católi-
cas de la iglesia latinoamericana.

${ }^{3}$ Para profundizar sobre este concepto ver Han (2012, pp. 27-28; 2014, pp. 41-42). 
compaginación ideológica con corrientes del conservadurismo y con una política de ultraderecha que permite una práctica católica fuertemente individual y emprendedora de $s i{ }^{4}$ por tanto, no es de extrañar que el fenómeno católico local contemporáneo encuentre en el conservadurismo y, a su vez, en el neoliberalismo, unos aliados ineludibles para mantener su hegemonía política y para lograr contrarrestar al enemigo común: el comunismo. Aclarando, claro está que el contexto latinoamericano, cuando se analiza con detenimiento, revela la existencia de toda una multiplicidad de subgrupos y divisiones dentro de las prácticas locales que hacen muy complejo aplicar a cabalidad en lo local un discurso global.

Desde este panorama nace la tesis del presente trabajo, a saber, que existen contrariedades entre gran parte de la praxis local y la teoría global católica de los últimos tres pontífices, debido a la irrupción del neoliberalismo globalizado en la región y de la idea de progreso que va de la mano de la interpretación del mundo que hace el capitalismo tardío.

\section{Fundamentos filosóficos del neoliberalismo y su variable en América Latina}

La doctrina neoliberal se ha consolidado y diversificado alrededor del mundo. No obstante, señalar con claridady distinción cartesiana qué es el neoliberalismo se convierte en un ejercicio difícil de realizar. Por ello, proponemos entenderlo desde su multidimensionalidad, la cual nos permite ver que existen al menos cinco sentidos en los que el neoliberalismo suele ser comprendido. Estos son:

\footnotetext{
4 "Ahora, consecuencia del neoliberalismo, las estrategias y procedimientos que conforman el sujeto empresarial son correlato de las tecnologías de subjetivación en el ámbito educacional. El sujeto dócil y disciplinado da paso a un sujeto permanentemente en curso y empresario de sí mismo. Y por ello, tanto el currículo como las pedagogías imperantes responden a tal política de empresa" (Santiago, 2017 , p. 325).
} 
[1] el político, que suele identificarse como libertarianismo, que defiende el resurgimiento de las ideas liberales que protegen libertades individuales como límite al poder del Estado y en donde el individuo es eje del poder; [2] el económico, que defiende el Estado mínimo cuya función primordial es la garantía de las libertades individuales o derechos negativos [...] y postula las bondades del mercado; [3] la gobernanza, que puede entenderse como el tránsito de la teoría del neoliberalismo político y económico a la acción política conservadora cuando ejerce el poder, la cual constituye el desarrollo del modelo en la toma de decisiones administrativas y burocráticas por parte del poder constituido; [4] en un sentido ideológico se hace referencia al neoliberalismo en forma negativa y peyorativa y, [5] finalmente, desde una perspectiva teórica crítica, el neoliberalismo se entiende como el predominio de la subjetividad del homo oeconomicus. ${ }^{5}$ (Pabón et al., 2019, p. 214)

Lo anterior evidencia que la fuerza que construye el neoliberalismo es un andamiaje teórico-práctico con dirección al completo desarrollo de las capacidades y las competencias humanas a partir de la desregulación de todo tipo de límites que puedan intervenir en el crecimiento libre e individual del ser humano. En este sentido, "la organización de una sociedad capitalista supone implícitamente que diferentes personas tienen diferentes fines y que las instituciones de la sociedad deben permitir esa diferencia” (Friedman, 1995, p. 33).

El modelo de ser humano que va de la mano de este sistema predomina por tener un entendimiento de sí mismo y de los demás en el que: "las funciones humanas esenciales

\footnotetext{
${ }^{5}$ En este orden de ideas, este artículo tiene en cuenta la quinta acepción, ya que es la que mejor permite entender las dinámicas de la racionalidad neoliberal dominante dentro del contexto latinoamericano.
} 
serían las de poseer, intercambiar, acumular y consumir. Los hombres actuarían o deberían proceder guiados por el egoísmo, y la conducta adecuada sería el cálculo de maximización de beneficios y minimización de costos" (Vergara, 2003, p. 6). La lógica neoliberal ordena, entonces, una competencia total entre seres humanos, competencia que, según los neoliberales, forma parte de la naturaleza humana desde sus inicios y ha de ser la cualidad guía dentro del sistema político, económico y social en que se viva. ${ }^{6}$ Como ya se ha mencionado en otro estudio, esto último

trae como consecuencia que a partir de este modelo [neoliberal] se orienta la comprensión de todos los episodios de la vida en términos de inversión y apreciación de capital, en donde, incluso, las personas se convierten en "recursos" o "capital humano". (Pabón et al., 2019, p. 216)

Así, se instituye un sistema que enaltece dos elementos que, según consideran los neoliberales, son propios de la naturaleza humana: desigualdad y competitividad. Esto se evidencia, por ejemplo, en el desprecio existente hacia las organizaciones sindicales en su lucha por los derechos sociales, como el salario y las prestaciones laborales, ya que la regulación de estos aspectos sería una intervención indebida al libre mercado y a los principios de respeto por la voluntad contractual y de igualdad ante la ley en aras de una supuesta discriminación positiva. Tal discriminación está ligada directamente, según los defensores del neoliberalismo, a una equivocada concepción de la justicia social que interviene en la naturaleza competitiva y desigual del ser humano (Vergara, 2003), como se puede apreciar en Hayek (1988): "No comparto algunos valores ampliamente sostenidos por los socialistas; pero no creo, como

${ }^{6}$ Ver von Mises (1994, p. 47). 
argumentaré más adelante, que la concepción generalizada de "justicia social" describa un posible estado de cosas o incluso sea significativa" (p. 8). ${ }^{7}$

La perspectiva neoliberal de comprender la realidad (en todas sus dimensiones), ligada fuertemente a la competitividad conlleva, entonces, la precariedad de la mayoría y la riqueza de la minoría. Esta lógica es justificada como la más adecuada para regir la economía del mundo a pesar de sus evidentes deficiencias:

Siempre existirán desigualdades que parecerán injustas a quienes las padecen, contrariedades que se tendrán por inmerecidas y golpes de la desgracia que quienes los sufren no han merecido. Pero cuando estas cosas ocurren en una sociedad deliberadamente dirigida, la reacción de las gentes será muy distinta que cuando no hay elección consciente por parte de nadie. La desigualdad se soporta, sin duda, mejor y afecta mucho menos a la dignidad de la persona si está determinada por fuerzas impersonales que cuando se debe al designio de alguien. En una sociedad en régimen de competencia no hay menosprecio para una persona, ni ofensa para su dignidad por ser despedida de una empresa particular que ya no necesita sus servicios o que no puede ofrecerle un mejor empleo. ${ }^{8}$ (Hayek, 2007, p. 142).

Ahora bien, en América Latina, este proceso se llevó a cabo de una forma particular. La aplicación de la doctrina en estos países fue un proceso que buscó reformar la manera en que se entendía la lógica de inversión estatal y la generación de capital en las grandes empresas de la región:

\footnotetext{
7 Esto para el neoliberalismo académico, pero para el neoliberalismo como gobernanza el odio a los sindicatos es por otro motivo: impedir la acumulación de riquezas.

8 Esto también es abordado por otros autores como von Mises (1986, pp. 394-395) y Friedman (1963, p. 107).
} 
La hegemonía neoliberal trastocó el modelo de los ajustes estructurales de los años ochenta, según el cual nuestras economías [latinoamericanas] se convirtieron en máquinas de pago de intereses internacionales en detrimento del consumo interno y del desarrollo. A continuación, en los años noventa, nos insertamos en el Consenso de Washington, que nos amarró a monedas sobrevaloradas, a los déficit comerciales y a las altas tasas de interés administradas por los Estados para captar el capital extranjero atraído por las reservas internacionales acumuladas durante las renegociaciones de la deuda externa, a finales de los ochenta, y por la privatización de nuestras empresas públicas. (Santos, 2005, p. 7)

Cierto es que no existe propiamente un "neoliberalismo latinoamericano" que sea objeto propio de estudio, lo que sí se puede pensar es la declinación neoliberal en América Latina, la cual no es más que los procesos y los resultados que generó (y genera) esta doctrina dentro de los países subdesarrollados latinoamericanos. La heterogeneidad que sufre el neoliberalismo en América Latina es una de estas cualidades de su declinación: "Cabe señalar que el neoliberalismo se implantó de distinta manera en cada país de América Latina [...] Por esa razón, el neoliberalismo fue un proyecto común pero heterogéneo en la región" (Vásconez, 2018, p. 101).9

Así, el neoliberalismo se convirtió en una fuerza hegemónica que se implantó en el modo latinoamericano de entender la política, la economía, la gobernabilidad y la ideología. Esta doctrina se convirtió en la directriz principal que daría sentido a todo acto dentro de los distintos países suramericanos que aplicaron sus modelos, esto último, en aras de dinamizar sus economías y sus políticas

9 Esta idea de la heterogeneidad neoliberal en América Latina se puede encontrar también en Chong y López (2005). 
por medio de la competitividad que ofrecían el "bienestar de mercado" y la teoría social de mercado, que no eran más que: "las propuestas económicas neoliberales de la liberalización del mercado, apertura comercial, ajuste estructural, privatización, desregulación e integración” (Jiménez, 1992, p. 6). ${ }^{10}$ Como resultado, se construyó una reorganización del Estado y sus instituciones, lo cual produjo una "limpieza" o "reducción" de las formas de bienestar estatal hacia los sectores con menor crecimiento económico y se redireccionó la política hacia un afianzamiento de los grandes capitales internacionales con los capitales nacionales (Jiménez, 1992), esperando que esto, a largo plazo, trajese desarrollo económico y social. ${ }^{11}$

Esto fue así debido a la cabida que tuvo este modelo neoliberal en tanto "alternativa" económica que prometía a los países subdesarrollados una guía con la cual poder generar crecimiento interno y fomentar la competitividad interna144 cional (Foxley, 1983). La propuesta inicial que se proyectó dentro de América Latina se postuló como el caso paradigmático para demostrar que, si se deja la libertad como un principio primero dentro de la sociedad (libre mercado), la economía tenderá al crecimiento y al equilibrio gracias a los esfuerzos individuales de cada persona en su búsqueda y competencia por el éxito personal; esto es, existe una fe llana en que: "el crecimiento económico individual genera mayores y mejores empresas [...] Por ello, buscar y proteger

${ }^{10}$ Esta conceptualización de la teoría social de mercado se puede encontrar en Hinkelammert (1984).

11 Sumado a esto es necesario delimitar cómo se entiende el sujeto neoliberal: "El sujeto pierde sus atributos, pues lo que prima es la racionalidad económica. Un sujeto que no cumpla con su rol de homo oeconomicus es irrelevante y puede prescindirse de él en cualquier momento" (Pabón et al., 2019, p. 215). Además, esta idea de sujeto neoliberal deja en claro que: "más que una ideología o un sistema de creencias que pone a actuar a los convencidos, el neoliberalismo es en realidad una especie de racionalidad con una estructura social concreta que cuenta con una serie de recursos, prácticas y estrategias dentro de las cuales se comprenden las personas" (Rico, 2019, pp. 162-163). 
desde el Estado la máxima satisfacción individual es [...] buscar alcanzar el desarrollo social de todos los individuos" (Millones, 2013, p. 60).

Sin embargo, la aplicación de dicho modelo no trajo los beneficios esperados ${ }^{12}$. Por el contrario, lo que desembocó a nivel general fue una crisis en grandes magnitudes que hoy en día aún es perceptible en lo que corresponde a los niveles de competitividad, crecimiento, bienestar social y calidad de vida (Villagra, 2015).

Esto último se puede sintetizar en los siguientes puntos:

1. Privatización extensiva de bienes, servicios y recursos nacionales.

2. Liberalización de precios de bienes y servicios ofertados a la sociedad.

3. Eliminación de subsidios estatales.

4. Eliminación de leyes sobre salarios mínimos a partir de la liberalización del factor trabajo.

5. Libre funcionamiento del mercado de dinero, trayendo como consecuencia incremento de las tasas de interés.

6. Eliminación de medidas proteccionistas a favor de las empresas transnacionales.

7. Liberación de la prioridad cambiaria, incrementando el éxodo de las reservas nacionales. ${ }^{13}$ (Torres, 2007, p. 2)

En este orden de ideas, es posible concluir que el proyecto neoliberal no fue el éxito que se prometió, sino un

12 Esto es algo que se puede apreciar en la investigación de Rojas (2015), en la cual se encuentran sistematizadas experiencias negativas sobre la aplicación en América Latina del modelo neoliberal.

${ }^{13}$ Sumado a estos puntos, también se debe agregar: "1. Reducción del déficit fiscal, sustentado en la disminución de la burocracia estatal. 2. Incremento de precios a mercancías hasta ese momento subsidiadas. (canastas básicas a sectores de más bajos ingresos). 3. Congelación de salarios. 4. Subidas de las tasas de interés, buscando incrementos en los ahorros. 5. Devaluación monetaria. 6. Favorecimiento al capital extranjero mediante adecuados intereses, con el fin de estimular la entrada al país de capitales extranjeros" (Torres, 2007, p. 3). 
sacrificio que terminaron pagando los sectores marginales de la sociedad. Las tesis capitalistas (en este caso expresadas en el neoliberalismo) expuestas al principio demostraron ser ineficaces en América Latina, puesto que al final no dejaron más que un caos económico en el que predomina una inequidad que refuerza la pobreza para la mayoría y genera riqueza para unos pocos. Dicho con otros términos, estas décadas de neoliberalismo en la región latinoamericana han dejado en claro que el modelo es muy útil para generar riqueza, pero pésimo para distribuirla (Rojas, 2015). Así se puede afirmar que lo que se aplicó en América Latina distó mucho de lo que pregonaron los académicos defensores del neoliberalismo.

\section{Prácticas neoliberales de la iglesia católica latinoamericana}

El mensaje que el líder del Vaticano promulga oficialmente a todos los seres humanos en general, y a los católicos del mundo en especial, es una forma de producir guía 146 y dirección espiritual, de modo que sea posible generar cierta homogeneidad en la práctica religiosa de lo que es el catolicismo. Por tanto, lo que se pretende con el mensaje papal es producir un principio de orden dentro de cada localidad donde el catolicismo tiene sede. Sin embargo, en la práctica, dicho mensaje puede no llegar a ser atendido de forma plena, correcta o, de plano, no ser considerado de ninguna forma. Lo ideal es la correspondencia entre discurso universal y práctica local, puesto que la Iglesia como una estructura institucional responde necesariamente a un orden jerárquico que permite gobernanza dentro de lo que es el catolicismo mismo. No son meros formalismos, sino una tradición que necesita de una correspondencia entre lo que se dice y lo que se hace. Aun así, la realidad es que dicha concordancia no existe en plenitud. Esto último, en parte, por los contextos tan disímiles en los que se ejercita el cristianismo, puesto que dentro de cada caso tienen lugar determinadas prácticas propias (heredadas de una 
tradición cultural, histórica, política, etc.) que hacen que el catolicismo, en este caso latinoamericano, sea un fenómeno variopinto; sin embargo, si se permite aquí generalizar, responde a ciertos denominadores comunes:

Esta afinidad entre la ideología liberal y el catolicismo se puede contemplar articulada desde cinco núcleos, a saber:

- La creación, de la que participa el hombre mediante su espíritu creativo que le permite construir la historia del mundo.

- El dinero, que cumple un papel importante, como factor histórico para el desarrollo económico querido por Dios. - La encarnación, mediante la cual Dios da respuesta a las necesidades humanas y que se prolonga en la satisfacción de las necesidades de consumo.

- La Trinidad que permite afirmar la unidad y la diversidad inherentes a la forma de vida del liberalismo.

- La caridad, centro del mensaje cristiano, que en el neoliberalismo se entiende como posible mediante un proceso de producción que permita la satisfacción de las necesidades humanas (Seminario de Profesores lnterfacultades Universidad Javeriana, ${ }^{14}$ 1998, p. 202).

Las prácticas religiosas son variadas y están muy condicionadas a los contextos sociales, políticos y económicos de cada localidad en la que se encuentran. Esto no quiere decir que todas las formas locales de expresión del catolicismo no respondan en concordancia con el discurso universal del papado, pero sí florecen formas particulares que contrastan de una manera que puede ser considerada contraria, o por lo menos distante, frente a los principios éticos y teológicos que el Sumo Pontífice predica (Roux, 2017, p. 48). Esto hace posible que existan posturas mixtas de todo tipo, pero siempre el ejercicio

14 En adelante SPIUJ. 
de la fe, en América Latina, está intervenido por un contexto específico, lo cual hace que existan grados de apoyo y reticencia con el discurso global que promulga el papa Francisco:

En la actual coyuntura cultural, católicos y protestantes llevan las de perder, especialmente los primeros, dada su fuerte estructura clerical, ante una religiosidad cada vez menos estructurada, más independiente y más sentimental. Piensan que tienen sólo una opción ante la alternativa de negociar con el neoliberalismo o lanzarse a la improvisación posmoderna.

Han optado por la negociación por dos causas principales: tienen un conocimiento parcial del sistema neoliberal y una conciencia insuficiente de sí mismos. (Vergara, 1997, p. 116)

Así pues, dentro de las prácticas contemporáneas de la Iglesia que se realizan dentro de lo local se intenta ser 148 consciente de las crisis que debe afrontar el mundo (tanto en el plano económico como en lo ecológico, social, político, etc.), además, a nivel regional es posible encontrar una postura reflexiva sobre el papel que juega la Iglesia dentro de dichas problemáticas que acosan al mundo. A nivel latinoamericano se puede apreciar que existe una acogida de la DSI, de su papel como alternativa a la acelerada sociedad de consumo que ha patrocinado el neoliberalismo globalizado; no obstante, también es fuerte la perspectiva contraria, ${ }^{15}$ aquella que recurre a una alianza con el conservadurismo y, por ende, con el neoliberalismo locales, para permitir permanencia y control territoriales:

15 Por ejemplo, Novak (1986) aclara, en su estudio sobre la teología de la liberación, que la Iglesia católica tiene que mantenerse alejada del socialismo y el militarismo de derecha, de modo que esta ayude a motivar al ciudadano para mejorar sus condiciones de vida. Esto último se alcanza con el progreso de los mercados y con una intensa atención en la economía libre (p. 253), dos condiciones que, desde la perspectiva del autor, solamente el capitalismo puede garantizar de mejor manera (pp. 231-307). 
Con la globalización, las religiones ancladas se desenvuelven en un campo dialéctico. Por una parte, deben emprender un proceso de desanclaje para evitar ser absorbidas por religiones en expansión étnico-geográfica, y por la otra deben emprender el desanclaje teniendo en cuenta que muchos de los rituales y mitos fundamentales de sus religiones están fundadas sobre sus espacios anclados de origen, y transformar su esencia eventualmente podría desembocar en su propia destrucción. (Gabriel, 2002, p. 66)

En este sentido, existe una neoliberalización de la DSI que caracteriza al catolicismo local donde predominan lo económico y lo mercantil. ${ }^{16}$ Es decir, el capitalismo, "que por ser altamente revolucionario de sus propias estrategias está en continua transformación” (Pabón et al., 2019, p. 2020), logra estructurar un modelo de la DSI que aparenta bienestar y desarrollo sostenible, pero realmente es una ilusión que propende a la propia reproducción del neoliberalismo. ${ }^{17}$

Haciendo un enfoque meramente en lo que corresponde al tema de estudio, las prácticas locales se encuentran con una mirada en paradoja, puesto que la posición de ciertos sectores de la iglesia responde a un apoyo a los pobres, a los necesitados y a los oprimidos, donde por extensión

\footnotetext{
${ }^{16}$ En este sentido, la economización defendida por ciertos sectores de la iglesia se asemeja con la teología de la prosperidad de los cultos protestantes de la región; esto es, el individuo y su bienestar económico se colocan en el centro del mundo, y la iglesia se convierte en un instrumento útil para la obtención de estos ideales centrales y para legitimar la fe individual, dejando de lado la solidaridad como base del evangelio. Esto último es algo que ha tomado fuerza y se ha asentado actualmente dentro de las prácticas locales, a nivel mundial, y que ha preocupado ampliamente al discurso universal de la Iglesia católica (Pellitero, 2019; Spadaro y Figueroa, 2019).

17 Algunos casos se pueden apreciar en Sweeney (1997), Cuevas (2007) y Blackman (2018). En estos trabajos se desarrollan éticas empresariales y corporativas desde puntos éticos de la DSI, pero, los autores de este escrito interpretan estas como una mera apariencia, ya que en su práctica no responden a lo postulado en su discurso y meramente existen para satisfacer la necesidad de un "desarrollo sostenible" exigido por el contexto global.
} 
se encuentran los trabajadores, los campesinos y las personas con vulnerabilidad económica, quienes componen la mayoría de la población en cualquier país de América Latina (y del mundo en general). Por otra parte, también está la mirada que encuentra en el conservadurismo tradicional y en el neoliberalismo unas formas de crecimiento más apropiadas a los principios de la Iglesia, además de ser aliados contra el enemigo común (el comunismo) y para garantizar estabilidad y hegemonía dentro del heterogéneo contexto latinoamericano. Así "nuevos sectores de la economía se están viendo reactivados debido a que lo religioso ha transformado sus lógicas financieras [...] haciendo emerger nuevos actores [...] los cuales se piensan como actores económicos y actúan como tales en el contexto neoliberal" (García, 2010, p. 94).

De este modo es posible caracterizar a aquellos católicos que son afines al conservadurismo y al neoliberalismo y que, sumado a esto, conforman un grupo considerable de movimientos que no encuentran en el progresismo de Francisco una dirección correcta para afrontar los retos del mundo actual. Por lo anterior, dichos movimientos encuentran en las políticas conservadoras, algunas de ultraderecha, una verdadera manera de confrontar a un mundo ausente de orden y principios sólidos (Wetzel, 2020). ${ }^{18}$ Estos grupos ven en el brazo fuerte de la economía una capacidad de redirigir el globo hacia un mejor futuro,

\footnotetext{
18 Históricamente, en América Latina ha sido evidente la relación entre algunos sectores ultraconservadores con diferentes políticas de corte fuertemente neoliberal (ver la nota de pie de página 21). Los sectores conservadores y neoliberales parecen llevarse muy bien, puesto que los primeros defienden la moral y los principios de trabajo, acumulación y riqueza que los segundos requieren para poder desenvolverse política, ideológica, subjetiva y gubernativamente (aludimos a las cuatro acepciones más comunes del neoliberalismo mencionadas al inicio). Ejemplo de lo anterior son Brasil (Flores, 2019), Argentina (Gudiño, 2017), Chile (Giraudier, 2015), Colombia (Camacho, 2008) y México (Ferraro, 2007). Estos estudios muestran la fuerte relación entre prácticas católicas locales y poderes estatales a favor de principios neoliberales.
} 
es decir, le apuestan a una idea de progreso de corte capitalista de derecha:

En síntesis, nos encontramos con un intento mundial de restablecer la integralidad del mensaje católico de Verdad en el seno de una sociedad secularizada en búsqueda de reencantamientos espirituales. Proyecto de penetración católica y religiosa en las estructuras sociales, políticas y culturales que se enfrenta a otros catolicismos de diálogo, conciliación y superación de las actuales culturas modernas capitalistas. (Mallimaci, 2005, pp. 42-43)

Aquí hay que dejar en claro lo siguiente, la Iglesia no tiene una única forma de ser. El sector católico en la región latinoamericana más dominante es el conservador y se ha aliado con el conservadurismo político y, a la par, con el neoliberalismo, ya sea porque comparten ideologías (es decir, creen que ser católico exige ser conservador en política y neoliberal en economía) o por pura conveniencia (el conservatismo político y el neoliberalismo económico son aliados necesarios, para bien o mal, para mantener el control y tener a raya a la izquierda). Pero hay otros sectores no tan poderosos, pero se hacen sentir, que consideran que ser católico implica una distancia (los moderados) o una crítica fuerte (los más radicales) al conservadurismo y al neoliberalismo. Podríamos decir que estos últimos son los hijos de la teología de la liberación y ciertas organizaciones religiosas consideradas de izquierda dentro de la propia Iglesia, como ciertos sectores de los jesuitas. ${ }^{19}$ Con lo dicho es posible dilucidar que dentro de las

19 Una complejidad que se evidencia en la investigación de Giménez (2020). Una sistematización de lo variopinta que es la práctica y el discurso religiosos, entre ellos (especialmente) el catolicismo, en América Latina en relación con el modelo neoliberal y las luchas sociales contra el capitalismo. Aunque se debe aclarar algo, la DSI es anticapitalista, pero del mismo modo anticomunista. 
prácticas locales de la Iglesia católica existe una afinidad desde un sector significativo hacia la doctrina neoliberal y, por extensión, hacia la ideología anticomunista de corte fuertemente derechista. ${ }^{20}$

Igualmente, existe una tendencia a la implementación de la DSI, asunto sobre el cual Francisco I constantemente llama a retomar frente a la lógica neoliberal o de (ultra)derecha que se encuentra en la mayoría de los sectores católicos de América Latina. El llamado de este tipo de prácticas católicas locales es el de aceptar la lógica neoliberal desde una mirada "humana" como un mal menor, de modo que la sociedad acepte los principios de la doctrina neoliberal desde una aparente sensación de bienestar, en la que el progreso, a pesar de ser entendido como una forma autodestructiva y salvaje de reducción de la dignidad humana (como señala Francisco), tenga apariencia de ser en aras del bien común, retorciendo los principios de la DSI. ${ }^{21}$

En este orden de ideas es posible rastrear dentro de las prácticas católicas locales una tensión entre su proceder religioso y el discurso oficial promovido por el Sumo Pontífice (el cual se expone en el siguiente apartado). Para estos sectores allegados a la derecha y al conservadurismo existe una necesidad de eludir el progresismo por su rechazo a los principios católicos tradicionales que han mantenido, hasta el momento, fuerte y estable a la Iglesia. La cercanía con el neoliberalismo es una afirmación de

\footnotetext{
20 Esto no exime la existencia de sectores que se ubican en la orilla contraria o en el punto medio entre ambas, pero lo que sí se puede decir es que esta línea de ultraderecha tiene acceso un peso considerable dentro de la esfera pública (Loaeza, 2013).

${ }^{21}$ Ejemplo de estos se puede ver en Giniger (2014) y Naranjo (2010), en que se pasa de la mirada conciliadora entre individualismo y colectivismo a una directa conciliación con el neoliberalismo por sobre todas las cosas, renunciando así al carácter de mediador que había mantenido el discurso universal de la Iglesia católica.
} 
los principios de crecimiento y progreso personal que posteriormente llevará a que exista un bienestar general que beneficiará la comunidad en general. Además, el concordar con esta doctrina permite mantener cercanía con la ideología y la política de corte conservador e incluso, en ciertos casos, ultraderechista ${ }^{22}$ que identifica el fenómeno neoliberal en América Latina:

La crítica latinoamericana del neoliberalismo [...] forma parte de un proceso de (re)descubrimiento y análisis de diversas variantes del pensamiento conservador y tradicional, habitualmente ignoradas o minimizadas por los intelectuales críticos en América Latina. Estos estudios críticos comprenden al catolicismo tradicional, realizado especialmente por los teólogos de la liberación, el discurso y práctica de las iglesias, las concepciones conservadoras, el decisionismo de Schmitt, las doctrinas de seguridad nacional y la geopolítica en América Latina, la evolución del pensamiento militar, etc. (Vergara, 2002, p. 9)

De modo que la síntesis entre las prácticas religiosas y la doctrina neoliberal, junto con la ideología ultraderechista, permite fomentar, lo que según entienden estos sectores, un catolicismo que sí da pie a solucionar las actuales crisis que enfrenta el mundo. Los principios del neoliberalismo permiten una interpretación del individuo como sujeto económico y políticamente libre, pero que para dar sentido a la existencia fuera de dichos planos recurre a un catolicismo fuerte en el cual puede encontrar el camino correcto para direccionar su progreso individual hacia un

\footnotetext{
22 Aclarando que hay ideologías de derecha y ultraderecha a favor del neoliberalismo, pero varios ultras son nacionalistas fuertes, por lo que no son neoliberales en sentido estricto, aunque en ciertos momentos, por motivos instrumentales, juegan juntos en la escena política.
} 
objetivo superior, es decir, se competitiviza la fe. ${ }^{23}$ Ejemplos de lo anterior se pueden encontrar en las dictaduras de derecha en América Latina, en las que el catolicismo, con honrosas excepciones, jugó un papel fundamental en aras de aportar bases teológicas a los regímenes, parecido a lo que en los 1990 ha hecho en relación con la sociedad neoliberal al defender un plano de competitividad más allá de lo terrenal:

Existe una intención legitimadora del neoliberalismo en la ética teológica contemporánea; se trata de una corriente que quiere legitimar el orden establecido y para eso se basa en la interdependencia entre los subsistemas económicos, político y cultural. Desde la teología de la liberación norteamericana, que se encuentra articulada a la división de poderes del Estado liberal, el neoliberalismo representa la auténtica liberación. Se quiere ver que la afinidad entre lo económico y lo religioso no se agota entre la ética protestante y el espíritu del capitalismo, sino que este último también resulta afín al catolicismo. (SPIUJ, 1998, pp. 201-202)

Las prácticas locales actuales son hijas de ese anticomunismo y ese rechazo a las formas progresistas de

${ }^{23}$ Esto es algo que la investigación de Zizek (2005) encuentra en el núcleo mismo de la ideología católica, específicamente, y del cristianismo, en general: "lejos de ser la religión del sacrificio, de la renuncia a los placeres terrenales (a diferencia de la afirmación pagana de la vida de las pasiones), el cristianismo ofrece una compleja estratagema para abandonarnos a nuestros deseos SIN TENER QUE PAGAR POR ELLOS, para disfrutar de la vida sin temer la decadencia y el extenuante dolor que nos espera al final del día" (p. 71, el texto en mayúsculas es de la fuente original). Además, la investigación de Sung (1999), igualmente, encuentra en la lógica de ciertas estructuras cristianas, específicamente católicas, una relación estrecha entre mercado, globalización y fe (pp. 34-37). Aunque hay que aclarar que existen sectores de la Iglesia, tanto a nivel global como local, que son muy críticos con la teología de la prosperidad y su visión del mundo, en especial con el capitalismo neoliberal que dicha teología protestante promociona: Hoffman (2020), Tancara (2020), Rosales (2020) y Cervantes (2020), por citar algunos de los más recientes. 
la política. ${ }^{24}$ Esto se suma al modo en que la ideología conservadora y ultraderechista también comparte muchas de las interpretaciones y las decisiones de la iglesia sobre otros temas, como el aborto y la eutanasia entre otros (Ferrero, 2009). Por lo que la postura pro neoliberal que existe dentro de muchas prácticas católicas en América Latina no es contraria a los principios que propone y presenta la Iglesia, sino que es síntesis prácticamente esperable tras todo el pasado histórico de la región. Ejemplo de esto último es lo expuesto por Donatello (2011), Rodeghero (2002) y González (1996). ${ }^{25}$ Todo esto conduce a que exista, en este orden de ideas, una crítica a Francisco I y su interpretación de cómo debe ser la práctica del creyente sobre temas como lo económico y lo político.

\section{Discurso global antineoliberal de la Iglesia católica}

Oficialmente, la Iglesia católica ha mantenido una postura en la que primero se reflexiona y luego se crítica los nuevos cambios que ha sufrido el mundo desde finales del siglo pasado. El Vaticano, en tanto que cabeza de la Iglesia, no ha sido ajeno a las transformaciones que los fenómenos como la globalización y la digitalización han producido en la vida cotidiana de la humanidad (Pillay, 2017). Hablando en términos de posición institucional, los Papas (tanto Juan Pablo II como Benedicto XVI y Francisco I) han sido partícipes en un

${ }^{24}$ Novak (1995) es consciente de esta idea del nuevo tipo de capitalismo por venir que reemplazaría la ideología de izquierda tras la caída de la URSS (pp. 200-259). El pensamiento de Novak respecto a las práticas católicas por venir en el cambio de siglo pone al capitalismo y sus principios como la base político-económica que deberá seguir la Iglesia si quiere llevar a los creyentes de la mano hacia el futuro, mostrando así alguna cercanía con los principios de la teología de la prosperidad.

${ }^{25}$ Estos estudios constituyen un claro ejemplo de la relación entre capitalismo neoliberal y prácticas católicas. Claro está que dichos estudios no afirman tajantemente un vínculo necesario entre ambos, por la carga ideológica y el compromiso político que conllevarían hacerlo, pero sí aluden a una manera de entender al ser humano que, si se sigue a Novak, exige una relación entre capitalismo y religión, bajo el principio de individualidad que garantice el bienestar del creyente. A esto se le denomina teología del capitalismo democrático (Novak,1982, pp. 237-360). 
proceso constante de actualización de la DSI; ${ }^{26}$ esto es, estas cabezas de la Iglesia católica, desde los principios propios de la fe cristiana, han seguido fieles a su defensa hacia una interpretación teológica de lo que es la justicia social en contra de la visión liberal económica (Vasa, 2016).

Por tanto, es menester exponer de forma general, por cuestiones de espacio, el modo en que cada Papa estructura un discurso crítico frente a lo que es el neoliberalismo, de modo que sea posible entrever la manera en que la Iglesia católica, en su mensaje global (por su validez universal), proyecta una fuerte resistencia con los procesos nocivos que conlleva un capitalismo salvaje y su expresión hegemónica actual desde el neoliberalismo. Esto último antes de exponer lo que es el eje fundamental de la crítica católica global a la lógica económica del rendimiento y la competitividad, a saber, la DSI:

El amor cristiano impulsa a la denuncia, a la propuesta y al compromiso con proyección cultural y social, a una laboriosidad eficaz, que apremia a cuantos sienten en su corazón una sincera preocupación por la suerte del hombre a ofrecer su propia contribución. La humanidad comprende cada vez con mayor claridad que se halla ligada por un destino único que exige asumir la responsabilidad en común, inspirada por un humanismo integral y solidario: ve que esta unidad de destino con frecuencia está condicionada e incluso impuesta por la técnica o por la economía y percibe la necesidad de una mayor conciencia moral que oriente el camino común. (Pontificio Consejo de Justicia y Paz, 2004, p. 17)

Con Juan Pablo II (1978-2005), a pesar de su marcado conservadurismo, es posible encontrar un discurso inicial de

26 Esto se puede notar en los contenidos de sus escritos, como lo son Benedicto XVI (2007), Juan Pablo II (1987) y Francisco (2019), por citar algunos. 
necesidad de cambio frente al modo de entender el progreso industrial y económico de la humanidad: "La Iglesia considera deber suyo recordar siempre la dignidad y los derechos de los hombres del trabajo, denunciar las situaciones en las que se violan dichos derechos, y contribuir [...] para que se realice un auténtico progreso del hombre” (Juan Pablo II, 1981, p. 3). ${ }^{27}$ Cierto es que el líder del Vaticano de ese momento no señaló directamente el neoliberalismo o al sistema capitalista como el origen de dichos males, lo que logró fue consolidar una postura crítica frente a múltiples fenómenos que comenzaban a florecer en el mundo:

Hoy este anuncio es particularmente urgente ante la impresionante multiplicación y agudización de las amenazas a la vida de las personas y de los pueblos, especialmente cuando ésta es débil e indefensa.

A las tradicionales y dolorosas plagas del hambre, las enfermedades endémicas, la violencia y las guerras, se añaden otras, con nuevas facetas y dimensiones inquietantes. (Juan Pablo II, 1995, p. 3)

De modo que, dentro de este tiempo que estuvo bajo la dirección de Juan Pablo II, la Iglesia fue consciente del momento histórico que se desarrollaba en distintos niveles de ese mundo que debían conducir hacia la salvación. En este marco de tiempo, la acción y discurso de la Iglesia se centró en dar voz a una serie de necesidades que estaban comenzando a tener un carácter sintomático al interior de la sociedad. Juan Pablo II, como testigo del auge fuerte del capitalismo en su expresión neoliberal en los 1980, 1990 e inicios del siglo XXI,

27 Esto también se puede apreciar en la Carta encíclica Redemptor hominis: "Nuestro siglo ha sido hasta ahora un siglo de grandes calamidades para el hombre, de grandes devastaciones no solo materiales, sino también morales, más aún, quizá sobre todo morales [...] es necesario constatar que hasta ahora este siglo ha sido un siglo en el que los hombres se han preparado a sí mismos muchas injusticias y sufrimientos" (Juan Pablo II, 1979, p. 23). 
fue propositivo al señalar que dentro de los modos en que los Estados e instituciones (tanto nacionales como internacionales) estaban pensando y dirigiendo el mundo se podía terminar desembocando en una crisis que le costaría a la humanidad y la Tierra su condición de bienestar. Un ejemplo concreto llega a ser lo expuesto en Centesimus annus:

Para superar la mentalidad individualista, hoy día tan difundida, se requiere un compromiso concreto de solidaridad y caridad [...] Pero ocurre que cuando la familia decide realizar plenamente su vocación, se puede encontrar sin el apoyo necesario por parte del Estado, que no dispone de recursos suficientes. Es urgente, entonces, promover iniciativas políticas no sólo en favor de la familia, sino también políticas sociales que tengan como objetivo principal a la familia misma, ayudándola mediante la asignación de recursos adecuados e instrumentos eficaces de ayuda, bien sea para la educación de los hijos, bien sea para la atención de los ancianos, evitando su alejamiento del núcleo familiar y consolidando las relaciones entre las generaciones. (Juan Pablo II, 1991, p. 42)

No obstante, la responsabilidad de señalar y cuestionar directamente la reducción económica y competitividad que vendría con la modernidad tardía sería del papado de Benedicto XVI (2005-2013). Es importante argumentar que durante este papado la Iglesia mantuvo el tono conservador de su predecesor, ${ }^{28}$ lo que le significó confrontaciones ideológicas con sus sectores más progresistas; ${ }^{29}$ sin embargo, eso no lo inhabilitaría para

\footnotetext{
${ }^{28}$ Cabe aclarar que en la presente investigación se niega el lugar común de ciertos sectores de la izquierda radical que señalaban a ambos papas (Juan Pablo II y Benedicto XVI) como representantes de una Iglesia católica neoliberal. Por el contrario, como se ve a lo largo de este acápite, su crítica frente al modelo económico de corte capitalista es incisiva, aunque su postura era conservadora (distinta a neoliberal), algo que los mantenía alejados de la izquierda, en otras palabras, su apuesta es por una teoría y una práctica desde un justo medio, de ahí el rechazo a ambos extremos.

${ }^{29}$ Ver Ellingsen (2005).
} 
fomentar una perspectiva crítica y reflexiva frente a los catastróficos fenómenos económicos, sociales y políticos que enfrentó el mundo durante dicho pontificado. Por el contrario, fue con este Papa que se señaló directamente al responsable de dicho rumbo destructivo que estaba tomando el mundo, a saber, la indetenible maquinaria capitalista que, desde su expresión neoliberal, ya se ejercía en el mundo de forma hegemónica:

En nuestra época, el Estado se encuentra con el deber de afrontar las limitaciones que pone a su soberanía el nuevo contexto económico-comercial y financiero internacional, caracterizado también por una creciente movilidad de los capitales financieros y los medios de producción materiales e inmateriales. Este nuevo contexto ha modificado el poder político de los estados. (Benedicto XVI, 2009, p. 14)

Así, dentro del papado de Benedicto XVI se puede ver un señalamiento y un llamado de atención a lo que es un sistema que está en un proceso de promoción de un estilo de vida que no va acorde con los principios cristianos que propenden a una redención de la humanidad. ${ }^{30}$ Durante este tiempo el discurso de la Iglesia se encuentra en una segunda fase, ya no solamente toma una consciencia de los cambios acelerados que está sufriendo el mundo en su estado de modernidad tardía, sino que ya señala de forma concisa un origen y pone en cuestión la manera como este sistema satura todas las dimensiones de la existencia humana (Hopper, 2009).

\footnotetext{
${ }^{30}$ Esto se puede apreciar en Pabst (2012), que destaca que, frente a una nueva crítica desde los sectores más allegados al capitalismo, Benedicto fue el precursor de una Tercera vía católica. También esto se puede ver en la Deus caritas est: "El surgir de la industria moderna ha desbaratado las viejas estructuras sociales y, con la masa de los asalariados, ha provocado un cambio radical en la configuración de la sociedad, en la cual la relación entre el capital y el trabajo se ha convertido en la cuestión decisiva, una cuestión que, en estos términos, era desconocida hasta entonces. Desde ese momento, los medios de producción y el capital eran el nuevo poder que, estando en manos de pocos, comportaba para las masas obreras una privación de derechos contra la cual había que rebelarse" (Benedicto XVI, 2005, p. 17).
} 
Finalmente, ya con Francisco I es posible encontrar un tercer momento de corte más activo en lo que corresponde a la ética y la práctica religiosa de la fe cristiana frente al neoliberalismo global que domina las formas de vida del ser humano. ${ }^{31}$ Hasta el momento se habían desarrollado dos episodios que correspondían cada uno a crear las bases para una crítica al capitalismo expresado en su forma neoliberal, y ya con la interpretación que hace este Papa del mundo es posible encontrar un llamado a la acción consciente para detener la aceleración incontrolable que el modelo hegemónico y deshumanizado ha producido en la sociedad, el cual él asocia directamente con el neoliberalismo. ${ }^{32}$

Francisco propone una crítica de corte ético-político que se complementa con una práctica que él ha impuesto sobre el Vaticano mismo (para que sirva de ejemplo), con miras a frenar la doctrina neoliberal que, según él, corroe la moral y los principios de la fe cristiana. ${ }^{33}$ Esta postura

${ }^{31}$ Parte del análisis de Fratelli Tutti resalta que Francisco I constituye una crítica al neoliberalismo de forma holística, esto es, tomando en cuenta las cinco acepciones mencionadas al principio. Esto se puede apreciar en la crítica al dogma de la fe neoliberal.

32 De hecho, Francisco I es el primero en utilizar el término "neoliberalismo" en una encíclica papal, además de directamente señalarla como culpable de la pobreza espiritual y material del ser humano: "El mercado solo no resuelve todo, aunque otra vez nos quieran hacer creer este dogma de fe neoliberal. Se trata de un pensamiento pobre, repetitivo, que propone siempre las mismas recetas frente a cualquier desafío que se presente. El neoliberalismo se reproduce a sí mismo sin más, acudiendo al mágico 'derrame' o 'goteo' -sin nombrarlo- como único camino para resolver los problemas sociales. No se advierte que el supuesto derrame no resuelve la inequidad, que es fuente de nuevas formas de violencia que amenazan el tejido social" (Francisco, 2020, p. 44).

33 En este sentido, habría que agregar como el papa Francisco ha articulado la DSI con el tema de los derechos humanos, lo que supone una denuncia a las dictaduras, a la xenofobia, a la discriminación, etc., como parte de la DSI. En papados anteriores, se vio omisión en la denuncia a las violaciones de los derechos humanos por parte de las dictaduras latinoamericanas e, incluso en ciertos casos, complicidad. Además, cabe destacar que el neoliberalismo, si bien es una ideología fundamentalmente económica, convive muy bien, a criterio de estos nuevos enfoques de la DSI, con la desigualdad y la opresión en otros órdenes, como en la política (con el autoritarismo camuflado de democracia), el género (con el patriarcado y la lgbtfobia), lo racial (con el racismo y la xenofobia), entre otros. 
antineoliberal que presenta Francisco es fundamento para la salvación y la redención del ser humano:

Dado que el mercado tiende a crear un mecanismo consumista compulsivo para colocar sus productos, las personas terminan sumergidas en la vorágine de las compras y los gastos innecesarios. El consumismo obsesivo es el reflejo subjetivo del paradigma tecnoeconómico [...] Tal paradigma hace creer a todos que son libres mientras tengan una supuesta libertad para consumir, cuando quienes en realidad poseen la libertad son los que integran la minoría que detenta el poder económico y financiero. En esta confusión, la humanidad posmoderna no encontró una nueva comprensión de sí misma que pueda orientarla, y esta falta de identidad se vive con angustia. Tenemos demasiados medios para unos escasos y raquíticos fines. (Francisco, 2015, p. 63)

Este nuevo Pontífice hace, además, un llamado claro y directo al creyente local, aquel que habita en los márgenes sociales, en la periferia, hacia un nuevo modo de entender el mundo más allá de la lógica consumista y capitalista que impera en el mundo. ${ }^{34}$

Bajo este papado, de un corte más progresista que sus antecesores, buena parte de los problemas globales tienen su origen en el descontrolado y salvaje sistema capitalista, que es expresado en la doctrina neoliberal que domina las dimensiones de la humanidad en

\footnotetext{
${ }^{34}$ Aunque se debe puntualizar en algo, a pesar de que todos los papas han dado un espaldarazo a la DSI, no tienen el mismo enfoque o el mismo interés al momento de hacer sus críticas al capitalismo. En este caso, Francisco I sería diferente de los anteriores. Esos matices diferenciadores afloran menos en cuestiones de política económica, y más en cuestiones relacionadas con derechos civiles y pautas identitarias. Es decir, el enemigo formalmente hablando siempre es el mismo (el liberal-capitalista y el comunista), pero lo que se entiende por capitalismo y la forma de enfrentarlo varía. En este sentido, desde un tema formal discursivo hay continuidad entre los papas, pero en cuanto a temas de contenido, hay rupturas.
} 
la actualidad, pero, contrario a los que lo antecedieron, Francisco I lleva la propuesta de la DSI a una posición vital y primordial para pensar la fe, tanto así que se vuelve una formulación global básica para practicar el catolicismo hoy día. ${ }^{35}$ Por ello, en la actualidad, el discurso universal de la Iglesia católica está directamente ligado con la crítica al capitalismo salvaje de aspecto neoliberal globalizado que ha absorbido, inundado, saturado y descartado, según la Iglesia, la vida digna del ser humano: "Se considera al ser humano en sí mismo como un bien de consumo, que se puede usar y luego tirar. Hemos dado inicio a la cultura del 'descarte' que, además, se promueve" (Francisco, 2013a, p. 17). ${ }^{36}$

Así pues, es posible recurrir a varias interpretaciones de lo que son los principios que componen el discurso global de la Iglesia frente al modelo hegemónico. De modo que se tiene: (1) dignidad humana, (2) subsidiaridad, (3) solidaridad, y (4) bien común y justicia social. Estos puntos son elementos ineludibles a la hora de entender el complejo pensamiento teológico sobre lo social, lo económico, lo político y hasta la vida en común. Sin embargo, su interpretación varía según cada región donde se acoja.

\footnotetext{
35 Para Francisco, el ser católico y creer en la fe cristiana tiene que ir ligado a la práctica de la DSI, solamente con ella es posible llevar el mundo tardomoderno a un verdadero goce divino. Lo teológico y lo eclesial se enlazan directamente con lo social, y existe un retorno discursivo y ético del catolicismo hacia la importancia de la justicia social no solo como una teoría contemplativa del mundo, sino como una doctrina de cambio y revitalización de la fe (Francisco, 2013b).

${ }_{36}$ Así, para el Papa, el principio de caridad se impone sobre el principio de competitividad que la fe neoliberal suscita en el pueblo, de ahí que la propuesta de Francisco I sea la de una caridad social: "Reconocer a cada ser humano como un hermano o una hermana y buscar una amistad social que integre a todos no son meras utopías. Exigen la decisión y la capacidad para encontrar los caminos eficaces que las hagan realmente posibles. Cualquier empeño en esta línea se convierte en un ejercicio supremo de la caridad [...] Se trata de avanzar hacia un orden social y político cuya alma sea la caridad social" (Francisco, 2020, p. 48).
} 
El principio de dignidad humana es el primer que, de forma directa, arremete contra la doctrina neoliberal tal cual como aquí se ha entendido. Es meritorio decir que, si bien el neoliberalismo defiende una igualdad formal ante la ley y la plena autonomía contractual, la propuesta universal de la Iglesia responde a una noción de dignidad que está por encima de lo que es la propuesta capitalista neoliberal, ya que la fe cristiana, en su DSI no solo piensa en clave terrenal el concepto de dignidad, sino que lo postula como un elemento fundamental de toda acción humana hacia los otros. Dicho de otro modo, es un principio del ser humano en tanto que creación divina, en convivencia con otros hijos de Dios, por lo que no es solamente un ente regulador de las relaciones de libre cambio:

La doctrina social de la Iglesia, aun reconociendo al mercado la función de instrumento insustituible de regulación dentro del sistema económico, pone en evidencia la necesidad de sujetarlo a finalidades morales que aseguren y, al mismo tiempo, circunscriban adecuadamente el espacio de su autonomía. (Pontificio Consejo de Justicia y Paz, 2004, p. 215)

Dentro de la subsidiaridad (segundo principio), del mismo modo se encuentra un rechazo a la propuesta de que el libre mercado salvaje y desregulado va a traer beneficios en general para la comunidad; sin embargo, también encuentra poco posible la idea de que el colectivismo excesivo, de corte socialista o comunista, puede conducir al ser humano hacia el éxito rotundo tanto en el plano terrenal como en el divino. Este segundo principio plantea, por un lado, una reducción del Estado como actor pasivo y, por el otro, una vida en comunidad reducida y controlada; esto es, los cuerpos institucionales de gran tamaño, como el 
Estado, los sindicatos, las organizaciones, la Iglesia, etc., existen pero únicamente para empoderar a los individuos a conseguir sus objetivos. No obstante, el individuo no es un ser autónomo en su totalidad, sino que vive en comunidad con otros en un plano reducido (en una "casa común”, diría Francisco), ${ }^{37}$ de modo que sea posible un crecimiento controlado de la vida humana, existiendo así un progreso, pero limitado a pequeños cuerpos sociales, en otras palabras, lo que hay es una comunidad semirregulada (Sadowsky, 1987).

Igualmente, la solidaridad (tercer principio) es un unificador de las sociedades semirreguladas propuestas anteriormente. Desde la interpretación católica, este concepto es un articulador de la humanidad; es aquel que permite, en su extensión, la comprensión del bien común. Esta dupla (solidaridad y bien común) hace que el ser humano esté unido al resto de la humanidad de modo tanto colectivo como individual. Así esta unión de conceptos propicia que la vida humana tenga una direccionalidad hacia Dios.

Finalmente, derivada del bien común, se encuentra la justicia social. Esta última se entrelaza directamente con el modo en que se entiende la cultura y la calidad de vida, además de que indirectamente también articula los demás principios, ya que promueve el modo en que la economía debe de estar para promover la justicia social, la cual aquí se asocia de forma directa con la adecuada distribución de los recursos disponibles tanto en las instituciones como en las comunidades semiautónomas.

Cabe mencionar que el discurso global de la Iglesia se propone como una alternativa no ideológica: no quiere (ni debe) estar atada ni a izquierda ni a la derecha, pues los

\footnotetext{
${ }_{37} \mathrm{Al}$ respecto, Francisco hace un llamado en general a la humanidad al desafío de cuidar la casa común (Francisco, 2015, p. 12).
} 
modos de Dios responden a sí mismos y no a agendas políticas, ${ }^{38}$ por lo que el rechazo al sistema neoliberal se hace en la misma medida que rechaza el comunismo.

\section{Conclusión}

Con lo dicho hasta el momento es posible denotar que existe una tensión entre el discurso universal que propone la Iglesia católica (encabezada por el Papa) de talante fuertemente antineoliberal y las prácticas católicas que se llevan a cabo en América Latina. ${ }^{39}$ La primera de estas tensiones se debe a la necesidad de "renovación" que viene de la mano de las transformaciones sociales, políticas y económicas que afronta el mundo, las cuales hacen que la injerencia del Vaticano, a pesar de su figura de autoridad, no sea tan fuerte como se esperaría dentro del desarrollo de las prácticas católicas latinoamericanas en relación con el neoliberalismo globalizado. En otras palabras, la figura del Obispo de Roma, a pesar de su progresismo, tiene la capacidad de poner en jaque procesos de innovación, antisocialistas, que puede producir la Iglesia en la región: "La presencia de los NME [Nuevos Movimientos Eclesiales] en los países de la Región [Latinoamérica] tiende a contrastar iniciativas que surgieron en el marco de la Teología de la Liberación o de la Teología del Pueblo" (Suárez, 2014, p. 129).

Como segundo elemento a tener presente, y que deriva directamente del primero, la ética y las prácticas católicas locales se transfiguran, para volcarse más sobre la defensa

\footnotetext{
38 Esto es algo que Juan Pablo II deja muy en claro: "tendrá presente [la Iglesia] que un partido político no puede identificarse nunca con la verdad del Evangelio, ni puede, por tanto, ser objeto de una adhesión absoluta, a diferencia de lo que sucede con el Evangelio [...] el presbítero tendrá en cuenta ese aspecto relativo, aun cuando los ciudadanos de fe cristiana constituyan de forma plausible partidos inspirados expresamente en el Evangelio, y no dejará de empeñarse en hacer que la luz de Cristo ilumine también a los demás partidos y grupos sociales" (1993, p. 3).

39 Para una caracterización más a profundidad de las representaciones ver Soneira (2007, 2014).
} 
del capitalismo, de modo que la propuesta antineoliberal de Francisco I choca con las prácticas neoliberales latinoamericanas que se desarrollan día a día, prácticas que varios sectores de la iglesia respaldan.

Lo anterior se debe al giro progresista, si bien es cierto que moderado (desde la perspectiva de la Teología de la liberación), de Francisco frente a los distintos debates y crisis que afronta el mundo, un giro que se ve fuertemente amenazado al encontrarse con prácticas como las que expone la doctrina neoliberal o las de corte (ultra) conservador que se han adecuado a muchos sectores del catolicismo latinoamericano. Recordando que existe una complejidad a la hora de entender las prácticas locales que concurren en América Latina, esto hace que en algunos casos se crea que ser católico supone ser conservador y neoliberal.

Sumado a lo anterior, es posible apreciar como tercer elemento una interpretación de la ética expuesta en la DSI 166 a partir de parámetros neoliberales que, a la larga, vacían el contenido social propio de la DSI y lo reemplaza por una visión individualista del mundo económico, contrario a lo propuesto inicialmente, donde se propendía a la búsqueda solidaria del mayor beneficio posible para todos, por lo cual era posible concebir, desde la DSI, al capitalismo y al socialismo en negociación, fomentando que los principios sociales de la Iglesia católica estuvieran empapados de una profundidad en lo correspondiente a las dimensiones que conforman al ser humano.

Una cuarta tensión por delimitar corresponde a la ausencia de unificación entre el discurso universal y la práctica local. Para el discurso universal, por lo menos el propuesto desde el pontificado de Francisco, la unidad de la Iglesia debe de ser retomada para superar la fragmentación (tanto de la interpretación de la DSI como de la sociedad y las relaciones humanas) existente, pero esto no implica una totalización del discurso católico, sino una aceptación 
parcial de la pluralidad religiosa y del multiculturalismo actuales en aras de redirigir todas las fuerzas hacia la superación de los nuevos retos que el mundo enfrenta, en especial la de un neoliberalismo que pone en jaque la dignidad de la persona. Por el lado local lo que existe es una fragmentación de las prácticas y los discursos (no hay correspondencia entre lo que se dice universalmente con lo que se dice y se hace localmente). Las prácticas locales tienen en común una interpretación económica del mundo, máxime que en la globalización lo económico se torna central. En esta región, desde sus prácticas religiosas, se ven sectores (católicos y protestantes) que propugnan por construir un tipo de comunidad que no se fundamenta en la solidaridad propia del amor al prójimo, sino en la exaltación del beneficio personal, lo cual hace más profunda la fractura existente en la comunidad cristiana latinoamericana en general y católica en particular, una fractura que impide la existencia de una civilización del amor (Pérez, 2008).

Finalmente, a modo de quinta tensión, se debe mencionar la interpretación de la globalización que propone el discurso global de la Iglesia; a saber, se entiende este concepto como un fenómeno que no se puede detener, por lo menos no a corto plazo, sino contar con una alternativa moderada, distinta a la existente actualmente, en que se reconozca la dignidad de toda persona más allá de cómo se inserta en el sistema productivo capitalista. Sin embargo, dentro de las prácticas locales, como se mencionó anteriormente, el concepto de globalización se enlaza con el perfeccionamiento de la comunidad en un libre mercado mundial, donde predomina el individualismo por encima de la caridad, entendiendo esta última como una perspectiva holística del prójimo y no como una forma de empatía con el ser humano entendido como consumidor.

Así, quedan expuestas algunas tensiones existentes entre lo global y lo local de la Iglesia católica en su relación 
con el neoliberalismo. Cierto es que un análisis posterior permitiría una continuidad más extensa de estos cinco puntos descritos. De momento queda por decir que, en la actualidad, el discurso católico universal y sus prácticas locales se encuentran en un conflicto debido a los procesos de aceleración y la maximización del rendimiento económico que sufre la sociedad contemporánea, ${ }^{40}$ lo cual conlleva una fragmentariedad de los discursos y del poder institucional dentro de la Iglesia católica.

\section{Andrés Botero}

Doctor en Derecho por la Universidad de Buenos Aires y doctor en Derecho por la Universidad de Huelva. Especialista en Docencia Universitaria y en Contextualización PsicoSocial del Crimen. Abogado y licenciado en filosofía y letras. Profesor titular de la Escuela de Filosofía de la Universidad Industrial de Santander (UIS). Miembro del grupo de inves168 tigación Politeia de la UIS.

\section{Javier Aguirre}

Doctor y magíster en Filosofía por la Universidad Estatal de Nueva York. Especialista en Docencia Universitaria, abogado y filósofo. Profesor titular de la Escuela de Filosofía de la Escuela de Filosofía de la Universidad Industrial de Santander (UIS). Miembro del grupo de investigación Politeia de la UIS.

\section{Juan David Almeyda}

Filósofo por la Universidad Industrial de Santander. Estudiante de la maestría de filosofía de esta misma universidad. Profesor de la Escuela de Filosofía de la Escuela de Filosofía de la Universidad Industrial de Santander (UIS). Miembro del grupo de investigación Politeia de la UIS.

\footnotetext{
${ }^{40}$ Este conflicto es una particularidad que Han (2020) ya encuentra dentro de los procesos rituales que componen a la religión, procesos que no son posibles de compaginar con la aceleración y el rendimiento que produce el neoliberalismo.
} 


\section{Bibliografía}

ANDRADE, Gabriel. 2002. Las nuevas tendencias religiosas a partir de la globalización. Revista de Ciencias Sociales, v. 8, n. 1, pp. 62-74.

BENEDICTO XVI. 2005. Deus caritas est. Carta encíclica. Disponível em: https://bit.ly/3iBETlM. Acesso em: 1 agos. 2020.

BENEDICTO XVI. 2007. Sacramentum caritatis. Exhortación apostólica. Vaticano: La Santa Sede. Disponível em: https://bit.ly/3hW8UxW. Acesso em: 5 jun. 2020.

BENEDICTO XVI. 2009. Caritas in veritate. Carta encíclica. Vaticano: A Santa Sé. Disponível em: https://bit.ly/3zmPubb. Acesso em: 3 fev. 2020.

BLACKMAN, Anna. 2018. Moralizing neoliberalism? An analysis of the principle of subsidiarity in catholic social teaching. In: STILL, Carl; ROMPRÉ, Gertrude. (ed.), Turning to the world: social justice and the common good since Vatican II. Montreal: McGill-Queen's University Press, pp. 50-66.

CAMACHO. Javier Andrés. 2008. Estado y religión católica en Colombia. Derecho y realidad, n. 12, pp. 145-152.

CERVANTES, Leopoldo. 2020. La llamada "Teología de la Prosperidad": un análisis teológico introductorio y crítico. Vida y Pensamiento, v. 39, n. 2, pp. 175-210.

CHONG, Alberto; LÓPEZ, Florencio. 2005. Privatization in Latin America: myths and reality. Palo Alto: Stanford University Press/The World Bank.

CUEVAS, Ricardo. 2007. Las formas de la ética de los negocios: la síntesis o las formas propiamente dichas. La doctrina social de la iglesia cristiana. Contaduría y Administración, n. 221, pp. 195-210.

DONATELLO, Luis Miguel. 2011. Catolicismo y elites en la Argentina del siglo XXI: individualización y heterogeneidad. Estudios Sociológicos, v. 29 , n. 87 , pp. 833-855.

ELLINGSEN, Mark. 2005. Joseph Ratzinger (1927-): How conservative is Benedict XVI? Theology Today, v. 62, n. 3, pp. 388-398.

FERRARO, Joseph. 2009. La lucha de la Iglesia contra el comunismo: de León XIII al Segundo Concilio Vaticano. México: UAM-Iztapalapa.

FOXLEY, Alejandro. 1983. Latin American experiments in neoconservative economics. California: University of California Press.

FRANCISCO. 2013a. Evangelii gaudium. Exhortación apostólica. Vaticano:

La Santa Sede. Disponível em: https:/ / bit.ly/3iqVVTC. Acesso em: 28 mai. 2020.

FRANCISCO. 2013b. Lumen fidei. Carta encíclica. Vaticano: La Santa Sede. Disponível em: https:/ / bit.ly/3wWfB72. Acesso em: 24 jan. 2020.

FRANCISCO. 2015. Laudato si'. Carta encíclica. Vaticano: La Santa Sede.

Disponível em: https://bit.ly/3BjP0nY. Acesso em: 16 fev. 2020. 
FRANCISCO. 2019. La esperanza de los pobres nunca se frustrará.

Mensaje del Santo Padre Francisco. Vaticano: La Santa Sede Disponível em: https:/ /bit.ly/36T2cCd. Acesso em: 20 jul. 2020.

FRANCISCO. 2020. Fratelli Tutti. Carta Encíclica. Vaticano: La Santa Sede.

Disponível em: https://bit.ly/3eGn6sM. Acesso em: 20 out. 2020.

FRIEDMAN, David. 1995. The machinery of freedom: Guide to a radical capitalism. 2. ed. Chicago: Open Court.

FRIEDMAN, Milton. 1963. Capitalism and liberty. Chicago: The University of Chicago Press.

FLORES, Victor. 2019. La Iglesia Católica y su relación con los militarismos en Brasil. Revista Eletrônica Mutações, v. 11, n. 8, pp. 44-58.

GARCÍA, Jesús. 2010. Lo religioso, actor globalizado y globalizador. Virajes, n. 13, pp. 41-96.

GIMÉNEZ, Verónica. (org.). 2020. La religión ante los problemas sociales: Espiritualidad, poder y sociabilidad en América Latina. Buenos Aires: Clacso.

GINIGER, Nuria. 2014. Doctrina Social de la iglesia y responsabilidad social empresaria: ética y política del neoliberalismo. Religión y Sociedad, v. 24, n. 42, pp. 34-66.

GIRAUDIER, Élodie. 2015. Los católicos y la política en Chile en la segunda mitad del siglo XX. Revista del CESLA, n. 18, pp. 213-237.

GONZÁLEZ, Luis Esteban. 1996. La ética católica y el capitalismo en América Latina. Apuntes: Revista de Ciencias Sociales, n. 38, pp. 31-40. GUDIÑO, Pablo. 2017. La Iglesia Católica en tiempos de dictadura y transición democrática (1976-1989): Discursos sobre familia, sexualidad y aborto. Revista Pilquen,

HAN, Byung-Chul. 2012. Sociedad del cansancio. Tradução Arantzazu Saratxaga. Barcelona: Herder.

HAN, Byung-Chul. 2014. Psicopolítica. Neoliberalismo y nuevas técnicas de poder. Tradução Alfredo Bergés. Barcelona: Herder.

HAN, Byung-Chul. 2020. La desaparición de los rituales: una topología del presente. Tradução Alberto Ciria. Barcelona: Herder.

HAYEK, Friedrich. 1988. The fatal conceit: the errors of socialism. Chicago: Chicago University Press.

HAYEK, Friedrich. 2007. Camino de servidumbre. Tradução José Vergara. Madrid: Alianza.

HINKELAMMERT, Franz. 1984. Crítica a la razón utópica. San José:

Departamento Ecuménico de Investigaciones.

HOFFMANN, Martin. 2020. Tres errores fundamentales de la Teología de la Prosperidad. Vida y Pensamiento, v. 39, n. 2, pp. 65-78. 
HOPPER, John. 2009. From profits to ethics: pope calls for a new political and financial world order. The Guardian. Disponível em: https://bit.ly/2Toysdm. Acesso em: 3 de mai. 2020.

JIMÉNEZ, Edgar. 1992. Democracia y neoliberalismo: perspectivas desde América Latina. Sociológica, v. 7, n. 19, pp. 1-19.

JUAN PABLO II. 1979. Redemptor hominis. Carta encíclica. Vaticano: La Santa Sede. Disponível em: https://bit.ly/3kGvmwL. Acesso em: 8 jun. 2020.

JUAN PABLO II. 1981. Laborem exercens. Carta encíclica. Vaticano: La Santa Sede. Disponível em: https://bit.ly/2Uy2hc4. Acesso em: 24 abr. 2020.

JUAN PABLO II. 1987. Sollicitudo rei socialis. Carta encíclica. Vaticano: La Santa Sede. Disponível em: https://bit.ly/3hSLzwJ. Acesso em: 20 fev. 2020.

JUAN PABLO II. 1991. Centesimu Annus. Carta encíclica. Vaticano: La Santa Sede. Disponível em: https://bit.ly/3Bpt62P. Acesso em: 15 mar. 2020.

JUAN PABLO II. 1993. El presbitero y la sociedad civil. Audiencia general. Vaticano: La Santa Sede. Disponível em: https://bit.ly/3BreVKI. Acesso em: 19 jun. 2020.

JUAN PABLO II. 1995. Evangelium vitae. Carta encíclica. Vaticano: La Santa Sede. Disponível em: https://bit.ly/3eChboz. Acesso em: 10 fev. 2020.

LETELIER, Gonzalo. 2017. ¿Qué son los principios de la doctrina social de la Iglesia? Theologica Xaveriana, n. 183, pp. 85-111.

LOEZA, Soledad. 2013. Estados Unidos y la contención del comunismo en América Latina y en México. Foro Internacional, v. 53, n. 1, pp. 5-56.

MALLIMACI, Fortunato. 2005. Globalización y catolicismo: la mirada desde arriba y las relaciones cotidianas. In: BIDEGAÍN, Ana María; DEMERA, Juan Diego. (eds.). Globalización y diversidad religiosa en Colombia. Bogotá: Universidad Nacional de Colombia, pp. 31-60.

MALLIMACI, Fortunato. 2009. Globalización y modernidad católica: papado, nación católica y sectores populares. In: ALONSO, Aurelio. (org.). América Latina y el Caribe: territorios religiosos y desafíos para el diálogo. Buenos Aires: Clacso. pp. 109-139.

MILLONES, Mario. 2013. Neoliberalismo en América Latina: una interpretación desde la ideología en Žižek. Sociológica, v. 79, n. 28, pp. 51-78.

MINNERATH, Roland. 2008. The fundamental principles of social doctrine. The issue of their interpretation. In: ARCHER, Margaret; DONATI, Pierpaolo. Pursuing the common good: how solidarity and subsidiarity can work together. Paper apresentado no 14th Plenary Session of the Pontifical Academy of Social Sciences, Vaticano, 2 a 6 de maio.

NARANJO, Eduardo. 2010. Una nueva ética económica católica en respuesta al nuevo liberalismo. Convergencia, n. 53, pp. 177-203. 
NOVAK, Michael. 1982. The spirit of democratic capitalism. New York: Simon \& Schuster.

NOVAK, Michael. 1986. Will it liberate?: questions about liberation theology. New York: Paulist Press.

NOVAK, Michael. 1995. La ética católica y el espíritu del capitalismo. Tradução Centro de Estudios Públicos. Chile: Centro de Estudios Públicos. PABÓN, Ana Patricia; AGUIRRE, Javier Orlando; BOTERO, Andrés. 2019. Transformaciones de la educación producto del influjo del modelo neoliberal: escuela sin atributos y jurisprudencia constitucional colombiana. Revista Logos: Ciencia E Tecnología, v. 11, n. 2, pp. 213-226.

PABST, Adrian. 2012. A Catholic third way: Pope Benedict and the crisis of global capitalism. ABC Ethics $\mathcal{E}^{\circ}$ Religion. Disponível em: https://ab.co/3xXZZRV. Acesso em: 15 jul. 2020.

PÉREZ, Bernardo. 2008. ¿Iglesia vs globalización? Hacia la civilización del amor. Veritas, v. 3, n. 18, pp. 181-208.

PELLITERO, Ramiro. 2019. Prosperidad y fe cristiana. Disponível em: https://bit.ly/36ODfIc. Almudi. Acesso em: 5 junh. 2020

PILLAY, Jerry. 2017. The church as a transformation and change agent. HTS Teologiese Studies/Theological Studies, v. 73, n. 3, pp. 1-12.

PONTIFICIO CONSEJO PARA LA JUSTICIA Y LA PAZ. 2004. Compendio de la doctrina social de la iglesia. Vaticano: Libreria Editrice Vaticana. Disponível em: https:/ /bit.ly/3y2eyUQ. Acesso em: 20 jun. 2020. RICO, David. 2019. Individuo, trabajo y neoliberalismo. Revista Filosofía $U I S$, v. 18, n. 1, pp. 151-170.

RODEGHERO, Carla. 2002. Religião e patriotismo: O anticomunismo católico nos Estados Unidos e no Brasil nos anos da Guerra Fria. Revista Brasileira de História, v. 22, n. 44, pp. 463-488.

ROJAS, Luis. (coord.). 2015. Neoliberalismo en América Latina. Crisis, tendencias y alternativas. Asunción: Clacso.

ROSALES, Sharo. 2020. La teología de la prosperidad y su impacto en la vida y espiritualidad de las personas. Vida y Pensamiento, v. 39, n. 2, pp. 79-108.

ROUX, Rodolfo de. 2017. La Iglesia católica en América Latina a la hora del papa Francisco. Caravelle, v. 108, pp. 35-49.

SADOWSKY, James. 1987. Capitalismo, ética y doctrina social católica clásica. Estudios Públicos, n. 28, pp. 49-61.

SANTIAGO, Ana. 2017. La sociedad de control: una mirada a la educación del siglo XXI desde Foucault. Revista de Filosofía, v. 73, pp. 317-336.

SANTOS, Theotonio dos. 2005. Del terror a la esperanza. Auge y decadencia del neoliberalismo. Tradução Amelia Hernández. Caracas: Monte Ávila Editores. 


\section{SEMINARIO DE PROFESORES INTERFACULTADES UNIVERSIDAD}

JAVERIANA. 1998. Neoliberalismo ideológico. Theológica Xaveriana, n. 48, pp. 191-212.

SONEIRA, Jorge Abelardo. 2007. Catolicismo, movimientos eclesiales y globalización en Latinoamérica. Revista Cultura y Religión, v. 1, n. 1, pp. 61-73.

SONEIRA, Jorge Abelardo. 2014. Catolicismo y globalización: El caso de los movimientos eclesiales en Argentina y Latinoamérica. In: AMEIGEIRAS, Aldo; MARTÍN, Pablo. Religión, política y sociedad. Buenos Aires: IDH-UNGS.

SUÁREZ, Ana. 2014. Nuevos movimientos y comunidades eclesiales “católicas” ¿Qué renuevan? Sociedad y Religión, v. 24, n. 42, pp. 92-131.

SPADARO, Antonio; FIGUEROA, Marcelo. 2019. Teología de la prosperidad. El peligro de un "evangelio diferente". Selecciones de Teología, v. 58, n. 231, pp. 243-250.

SWEENEY, John. 1997. La misión del empresario cristiano. Revista Empresa, n. 126, pp. 14-18.

TANCARA, Juan. 2020. "Dios no es un dios de pobres...": Teología de la Prosperidad como una de las teologías del mercado capitalista neoliberal. Vida y Pensamiento, v. 39, n. 2, pp. 149-174.

TORRES, Miguel. 2007. El neoliberalismo y sus consecuencias para América Latina. Ciencias Holguín, v. 7, pp. 1-8.

VASA, Robert. 2016. A consideration of social justice. The Linacre Quarterly, v. 83, n. 4, pp. 363-369.

VÁSCONEZ, José Emílio. 2018. Política neoliberal en América Latina e inversión en asociaciones público-privadas para infraestructura. Comentario Internacional: Revista del Centro Andino de Estudios Internacionales, n. 18, pp. 97-123.

VERGARA, Jesús. 1997. Inautenticidad neoliberal en las iglesias. Análisis Plural, n. 2, pp. 107-119.

VERGARA, Jorge. 2002. La contribución de Hinkelammert a la crítica latinoamericana al neoliberalismo. Polis, n. 2, pp. 1-15.

VERGARA, Jorge. 2003. La utopía neoliberal y sus críticos. Polis, n. 6, pp. 1-25. VON MISES, Ludwig. 1986. La acción humana. 4. ed. Tradução Luis Reig y Joaquín Reig. Madrid: Unión Editorial.

VON MISES, Ludwig. 1994. Liberalismo. Tradução Joaquín Reig.

Barcelona: Planeta De Agustini.

WETZEL, Dominic. 2020. The rise of the Catholic Alt-Right. Labor and Society, v. 23, n. 1, pp. 1-25.

ZIZEK, Slavoj. 2005. El títere y el enano: El núcleo perverso del cristianismo. Tradução Alcira Bixio. Buenos Aires: Paidós. 
Quien peca y reza empata 
QUIEN PECA Y REZA EMPATA: TENSIÓN ENTRE EL DISCURSO UNIVERSAL Y LAS PRÁCTICAS REGIONALES EN LA IGLESIA CATÓLICA EN RELACIÓN CON EL NEOLIBERALISMO LATINOAMERICANO

ANDRÉS BOTERO-BERNAL

JAVIER ORLANDO AGUIRRE-ROMÁN

JUAN DAVID ALMEYDA-SARMIENTO

Resumen: El presente trabajo tiene por objeto exponer las tensiones entre el discurso global antineoliberal y las prácticas regionales neoliberales dentro de la iglesia católica en América Latina. Para ello, primeramente, se exponen los principios del neoliberalismo y su aplicación en Latinoamérica a finales del siglo pasado e inicios del presente; en seguida, se muestran algunas prácticas locales a favor del neoliberalismo por parte de la iglesia católica latinoamericana; por último, se presenta el discurso de la Iglesia católica al respecto del neoliberalismo bajo los pontificados de Juan Pablo II, Benedicto XVI y Francisco I. Todo esto permite presentar un contraste entre el discurso global y la práctica local, así como exponer el desacople existente en la actualidad entre el discurso global y el local de la Iglesia católica con respecto al neoliberalismo.

Palabras clave: Iglesia Católica; Neoliberalismo; Globalización; América Latina.

\section{QUEM PECA E REZA OS LAÇOS: TENSÃO ENTRE DISCURSO UNIVERSAL E PRÁCTICAS REGIONAIS NA IGREJA CATÓLICA EM RELAÇ̃O AO NEOLIBERALISMO LATINO-AMERICANO}

Resumo: $O$ objetivo deste trabalho é expor as tensões entre o discurso antineoliberal global e as práticas regionais neoliberais da Igreja Católica na América Latina. Para atingir esse objetivo, três 
momentos são propostos: inicialmente, são expostos os princípios do neoliberalismo e sua aplicação na América Latina ao final do século passado e início do presente; a seguir, se apresentam as práticas locais neoliberais da Igreja Católica na América Latina; depois, é feita a exposição do que a Igreja Católica disse em seu discurso sobre o neoliberalismo dos pontificados de João Paulo II, Bento XVI e Francisco I. Tudo isso para apresentar um contraste entre as práticas locais e discurso global, além disso de florescer o conflito que atualmente existe entre ambos sobre um fenômeno econômico e político como o neoliberalismo.

Palavras-chave: Igreja Católica, Neoliberalismo, Globalização, América Latina.

\section{WHO SINS AND PRAYS EVENS SCORE: TENSION BETWEEN UNIVERSAL DISCOURSE AND REGIONAL PRACTICES IN THE CATHOLIC CHURCH IN RELATION TO LATIN AMERICAN NEOLIBERALISM}

Abstract: The purpose of this paper is to expose the tensions between the global anti-neoliberal discourse of the Catholic Church and the neoliberal catholic practices in Latin America. To achieve this goal, three moments are proposed: initially, the principles of neoliberalism and their application in Latin America at the end of the last century and beginning of the present are exposed; next, the neoliberal local practices of the Latin American Catholic Church are presented; later, the exposition of what the Catholic Church said in its global discourse regarding neoliberalism under the pontificates of John Paul II, Benedict XVI and Francis I is made. All this in order to present a contrast between these two (global discourse and local practice) by exposing the current disengagement between the global and local discourse of the Catholic Church with respect to neoliberalism.

Keywords: Catholic Church; Neoliberalism; Globalization; Latin American.

Recebido: 05/08/2020 Aprovado: 07/05/2021 